\title{
Anodontites trapesialis (LAMARCK, 1819): um bivalve parasito de peixes de água doce
}

\author{
Anodontites trapesialis (LAMARCK, 1819): \\ a bivalve parasite of freshwater fishes
}

\author{
Paula Guardia Felipi ${ }^{1}$; Ângela Teresa Silva-Souza ${ }^{2 *}$
}

Resumo

O molusco bivalve, Anodontites trapesialis, tem sido indicado como fonte alternativa para a aqüicultura, por ser considerado um alimento de bom valor nutricional com um conteúdo protéico próximo ao do pescado. Suas conchas podem ser utilizadas como fertilizantes calcáreos e ser agregadas a alimentos de animais domésticos e o nácar pode ser utilizado para fabricar botões e artesanatos. No entanto, as larvas de A. trapesialis, que são do tipo lasidium, são parasitas obrigatórias de peixes de água doce e a introdução desse bivalve em tanques de piscicultura tem causado transtornos e prejuízos aos produtores. Nada se conhece, porém, sobre o seu desenvolvimento nesses ambientes. Por outro lado, ressalta-se que $A$. trapesialis consta da lista brasileira de espécies ameaçadas de extinção. No presente artigo são compiladas as informações presentes na literatura, em uma revisão detalhada, com o objetivo de apresentar o panorama geral do conhecimento acerca de Anodontites trapesialis e do parasitismo de peixes por suas larvas.

Palavras-chave: Bivalve, Lasidium, parasita

\begin{abstract}
The bivalve mollusk Anodontites trapesialis has been indicated as an alternative source for aquaculture because it is considered a food of good nutritional value with a protein content close to that of fish. Its shells can be utilized as fertilizer and mixed to the food of domestic animals, and the nacre can be used to manufacture buttons and crafts. However, the larvae of $A$. trapesialis, which are the lasidium type, are obligatory parasites of freshwater fishes, and the introduction of this bivalve in fish farm tanks have caused trouble and losses for producers. Nothing is known, however, about their development in these environments. On the other hand, it should be pointed out that $A$. trapesialis is on Brazil's list of species threatened with extinction. This article provides a compilation of information present in the literature, offering a detailed review, with the aim of presenting a general panorama of what is known about Anodontites trapesialis and its larval parasitism of fishes.
\end{abstract}

Key words: Bivalve, Lasidium, Parasite

\footnotetext{
1 Bióloga, Mestre em Ciências Biológicas, Departamento de Biologia Animal e Vegetal, CCB, Universidade Estadual de Londrina, UEL. 86051-990, Londrina, PR.

2 Bióloga, Docente do Programa de Pós-Graduação em Ciências Biológicas, Universidade Estadual de Londrina, Departamento de Biologia Animal e Vegetal, CCB, 86051-990, Londrina, PR. E-mail: ateresa@uel.br

* Autor para correspondência
} 


\section{Histórico}

Os moluscos bivalves de água doce até hoje registrados no Brasil pertencem a dois grandes grupos: os da ordem Unionoida e os da ordem Veneroida. Os membros da ordem Unionoida apresentam larvas do tipo véliger modificado, que podem ser parasitos temporários de peixes em algumas espécies e, de acordo com particularidades morfológicas, são denominadas glochidium ou lasidium (MANSUR; SCHULZ; GARCES, 1987).

Em 1695, larvas dos bivalves foram registradas como pequenos parasitos das brânquias de peixes europeus. Posteriormente, em 1797, pequenos organismos encontrados na brânquia de mexilhões de água doce europeus foram descritos como Glochidium parasiticum e considerados parasitos desses animais. Somente em 1832 constatou-se que não se tratava de parasitos, mas das larvas dos próprios mexilhões incubadas nas brânquias. Entretanto, o termo glochidium foi mantido e persiste até os dias atuais como denominação das larvas de bivalves da superfamília Unionacea. (DILLON, 2000).

Por outro lado, o termo "lasidium" foi usado pela primeira vez apenas em 1891, quando Ihering descreveu a forma larval de Anodontites wymani Lea = Anodontites patagonica (Lamarck) (PARODIZ; BONETTO, 1963).

Até 1963, todos os moluscos bivalves perlíferos de água doce da América do Sul eram agrupados na superfamília Unionacea. Entretanto, para esta classificação, utilizava-se somente caracteres conquiológicos e anatômicos, desconsiderando as características larvais. Parodiz e Bonetto (1963) propuseram uma nova classificação com a criação da superfamília MUTELACEA, para congregar os bivalves com larvas do tipo lasidium, distinta embrionária e morfologicamente de glochidium, até então considerada comum a todos os unionóides.

Larvas do tipo lasidium são encontradas somente nas famílias Mutelidae na África e Mycetopodidae na América do Sul (PARODIZ; BONETTO, 1963;
WÄCHTLER; DEHER-MANSUR; RICHTER, 2001). Na família Mycetopodidae, além do gênero Anodontites, investigações revelaram também a presença de lasidium nos gêneros Monocondylaea, Mycetopoda e Leila (BONETTO; EZCURRA, 1965a).

$\mathrm{Na}$ América do Sul a maior parte dos estudos sobre os membros destas superfamílias é voltada aos aspectos anatômicos, morfológicos funcionais e à sistemática (MARSHALL, 1922; BONETTO, 1967; VEITENHEIMER-MENDES, 1973a, 1973b; MANSUR, 1974; HEBLING, 1976; MANSUR; SCHULZ; GARCES, 1987; CASTELLANOS; LANDONI, 1990; AVELAR, 1993; SIMONE, 1994; MANSUR; OLAZARRI, 1995; CALLIL; MANSUR, 2005; MANSUR; PEREIRA, 2006). Muitos dos trabalhos que fazem referência aos aspectos reprodutivos reportam-se principalmente à família Hyriidae, que possui larva do tipo glochidium (PEREDO; PARADA, 1986; AVELAR et al., 1991; AVELAR; MENDONÇA, 1998; MANSUR, 1999; BEASLEY et al., 2000).

De acordo com Avelar e Mendonça (1998), no Brasil, são poucos os estudos disponíveis quanto à gametogênese, ao tempo de incubação, à eliminação larval, aos peixes hospedeiros e à duração do parasitismo para a maioria das espécies de bivalves de água doce. Menos ainda é conhecido quanto aos bivalves com larvas do tipo lasidium.

\section{Características gerais de Mycetopodidae Gray, 1840}

De acordo com Castellanos e Landoni (1990), a família Mycetopodidae restringe-se à América do Sul, não sendo encontrada na sub-região andinopatagônica. Ocorre somente em água doce, em ambientes lênticos ou lóticos, embora segundo Simone (1994), dificilmente seja encontrada em locais com águas rápidas.

Os fatores que determinam a presença ou a ausência da população em uma determinada área são: 
- aqueles que afetem o deslocamento normal dos peixes hospedeiros no ambiente;

- características do substrato que permitirão ou não o assentamento e a sobrevivência do bivalve jovem;

- características físicas e químicas da água, como, profundidade, salinidade, teor de oxigênio diluído e porcentagem de matéria orgânica, entre outros;

- movimentação dos espécimes em função da erosão do substrato ou arraste das águas e capacidade dos mesmos para fixar-se em locais favoráveis e ajustar-se às novas condições ambientais.

Os bivalves micetopodídeos ficam semienterrados em sedimentos de variáveis composições granulométricas, com populações mais densas em fundos argilosos ou argilo-arenosos. Sua alimentação consiste geralmente de partículas em suspensão (plâncton e detritos orgânicos); consomem grandes quantidades de algas macroscópicas, sendo muito comuns as diatomáceas Navicula, Eunotia, Surirella, as cianofíceas, Oscillatoria, Lyngbya, Clorófitas, Scenedesmus e Cosmarium, as euglenófitas Euglena e Phacus, além de rizópodes e outros protozoários (CASTELLANOS; LANDONI, 1990). A água, com partículas em suspensão, penetra na cavidade do manto através da abertura inalante, onde é realizada a primeira seleção. Geralmente, nas espécies que habitam águas calmas e com finas partículas em suspensão, o bordo da abertura inalante é liso e com pequenas papilas (HEBLING, 1976; CASTELLANOS; LANDONI, 1990; AVELAR et al., 1991; AVELAR, 1993). Uma vez na cavidade paleal, as partículas são submetidas à ação ciliar das brânquias, onde se produz a segunda seleção e, daí são enviadas aos palpos labiais e para a boca (CASTELLANOS; LANDONI, 1990).

Na família Mycetopodidae a fertilização é interna e os ovos são incubados nas demibrânquias internas, em uma região modificada denominada "marsúpio" (CASTELLANOS; LANDONI, 1990). Durante a incubação, as demibrânquias internas continuam a reter e processar as partículas alimentares, mas com reduzida eficiência (TANKERSLEY, 1996 apud DILLON, 2000).

Na fêmea de Monocondylea minuana o marsúpio ocupa quase toda a demibrânquia interna, com exceção de uma estreita faixa ventral e alguns tubos aqüíferos na região anterior e posterior. Os ovos formam uma massa, a princípio compacta como um tubo, que é presa no marsúpio pelas pregas dos septos e, à medida que crescem, a massa torna-se mais frouxa (MANSUR, 1974).

Em Mycetopoda legumen a incubação ocorre nos marsúpios que ocupam as demibrânquias internas em sua metade anterior, excluída a extremidade (VEITENHEIMER-MENDES; MANSUR, 1978a).

A quantidade de ovos contida no marsúpio é elevada. Os ovos geralmente apresentam a forma esférica e o tamanho variável (CASTELLANOS; LANDONI, 1990).

O período de incubação varia entre as espécies. Em Monocondylea paraguayana ocorre entre os meses de outubro e janeiro(BONETTO; EZCURRA, 1963 apud CASTELLANOS; LANDONI, 1990) e, em Anodontites (Anodontites) soleniformes, Maldonado et al. (1990) encontrou ovos nas brânquias de janeiro a julho. Por outro lado, Bonetto (1951 apud CASTELLANOS; LANDONI, 1990), registrou a presença de larvas maduras de outubro a janeiro em espécimes de Anodontites trapesialis e Bonetto e Ezcurra (1962) constataram a presença de larvas de agosto a janeiro nas brânquias da mesma espécie.

Segundo Castellanos e Landoni (1990), os micetopodídeos servem de alimento para crustáceos como camarões e caranguejos, bem como para peixes de fundo como Rhynodoras d'orbigni, tartarugas, ratos d'água (Holochilus brasiliensis vulpinus) e aves como Aramus guarauna.

As conchas podem ser utilizadas como fertilizantes calcáreos e como cal forrageira para agregar aos alimentos de animais domésticos. O 
nácar é variável entre as espécies e pode ser utilizado para fabricar botões e artesanatos. Em raras ocasiões são capazes de produzir pérolas de boa qualidade (CASTELLANOS, 1965; CASTELLANOS; LANDONI, 1990).

\section{Anodontites trapesialis}

NoBrasil, a família Mycetopodidaeérepresentada por 12 gêneros, dos quais Anodontites Bruguière, 1792 apresenta o maior número de espécies (15) (SIMONE, 2006).

Nas espécies de Anodontites a forma da concha varia de oval a elíptica, com valvas subsólidas (ainda que geralmente frágeis pelo grande desenvolvimento da camada prismática), região posterior pouco projetada, com extremidade distal descendente, não afilada, pé de forma não cilíndrica em linguiforme (BONETTO, 1967; MANSUR; PEREIRA, 2006).

Anodontites trapesialis distingue-se das demais espécies pela forma trapezóide, valvas infladas e com espessura relativamente fina; região anterior mais baixa, com a extremidade anterior arredondada, porém levemente projetada acima da metade da altura; borda dorsal quase reta, a ventral arqueada e mais projetada ventralmente na metade posterior; umbos inflados e largos, com os bicos (extremidade distal dos umbos) pouco evidenciados; perióstraco varia do verde-claro ao verde-escuro, liso brilhante, podendo apresentar raios esverdeados; nácar prateado-esverdeado ou cinza-azulado, iridescente; capa prismática evidente, porém estreita(MANSUR; PEREIRA, 2006).

De acordo com Simone (1994), a anatomia de $A$. trapesialis foi inicialmente investigada por Simpson, em 1900. Posteriormente, foi mais completamente descrita por Veitenheimer (1973 apud SIMONE, 1994) e por Hebling (1976). Esses bivalves podem atingir grandes tamanhos, com alguns indivíduos chegando a mais de $20 \mathrm{~cm}$. Podem ser encontrados em ambientes aquáticos com até 20 metros de profundidade, mas geralmente estão entre 1 e $2 \mathrm{~m}$ de profundidade. Hebling (1976) observou que, em Anodontites trapesialis, a capacidade para cavar em substratos macios e ocupar o mesmo local por longos períodos de tempo pode estar associada à falta de funcionalidade do músculo dorsal.

As gônadas, nos espécimes de Anodontites trapesialis, estão localizadas na massa visceral, entre as curvas dos ductos alimentares (HEBLING, 1976). A espécie é caracterizada como hermafrodita funcional e simultâneo (CALLIL; MANSUR, 2007). Secções seriais de $A$. trapesialis revelaram gônada hermafrodita junto à glândula digestiva (SIMONE, 1994).

O ducto genital termina em duas aberturas, localizadas na região proximal anterior da demibrânquia interna, entre as lamelas ascendentes e descendentes. Cada abertura genital exibe uma papila voltada para a região posterior, exatamente abaixo da abertura renal. Assim, logo que são liberados, os produtos sexuais passam para a cavidade da demibrânquia interna e são movidos por um intenso movimento ciliar local (HEBLING, 1976).

Em Anodontites trapesialis os ovos são incubados na porção central junto à lâmina interna ou ascendente das demibrânquias internas (BONETTO; EZCURRA, 1962). Os septos branquiais apresentam expansões laterais que limitam aos tubos aqüíferos secundários contra a lâmina externa quando o animal está "grávido", os septos são mais delgados e se distendem amplamente para dar lugar à massa de ovos. As larvas maduras são eliminadas ao exterior através do sifão exalante (CASTELLANOS; LANDONI, 1990).

O número de ovos ou larvas contido nos marsúpios é elevado. Em um exemplar de tamanho médio (9,0 cm de comprimento), Bonetto e Ezcurra (1962) registraram um total de 3.500.000 larvas. Hebling (1976) encontrou um total de 3.200.000 em um espécime de $A$. trapesialis de $10,4 \mathrm{~cm}$. No entanto, pouco se conhece sobre a gametogênese e o ciclo reprodutivo dessa espécie. 
A espécie Anodontites trapesialis tem sido utilizada como bioindicadora em estudos de monitoramento ambiental. Dentre os trabalhos realizados no Brasil, destacam-se os de Lopes et al. (1992), que realizou um biomonitoramento de pesticidas organoclorados, de Callil e Junk (1999) que pesquisaram a concentração e a incorporação de mercúrio, de Jacomini (2002), que relatou a bioacumulação do herbicida atrazina, e de Tomazelli et al. (2003), com o biomonitoramento de chumbo e cádmio.

Alguns estudos têm apontado a espécie como fonte alternativa para a aqüicultura, por ser considerada como um alimento de bom valor nutricional com um conteúdo protéico próximo ao do pescado (TELLO-PANDURO et al., 2003; VIVANCO; ORDINOLA; TABOADA, 2003; TELLO-PANDURO et al., 2004).

\section{A Larva Lasidium}

A existência da larva lasidium permaneceu duvidosa por várias décadas, em função da dificuldade que os pesquisadores tiveram em encontrar ou reconhecer esta larva (PARODIZ; BONETTO, 1963). A "redescoberta" da larva foi relatada por Bonetto (1951, apud CASTELLANOS \& LANDONI, 1990), que fez uma descrição de lasidium de Anodontites trapesialis do rio Paraná.

Diferentemente de glochidium, que exibe basicamente o mesmo plano de organização nas espécies de todas as regiões geográficas, lasidium, nas espécies das famílias Mutelidae (África) e Mycetopodidae (América do Sul), passa por estágios de desenvolvimento iniciais semelhantes, mas difere significativamente ao longo do desenvolvimento (PARODIZ; BONETTO, 1963; WÄCHTLER; DREHER-MANSUR; RICHTER, 2001). Entre os caracteres morfológicos básicos presentes em lasidium das espécies das duas famílias destaca-se o corpo dividido em três regiões distintas: a anterior, com um par de lóbulos ciliados, quase sempre justapostos nas espécies americanas; a média, coberta por uma concha univalve não calcificada, e a região posterior formada por dois lobos curtos com cirros ou ganchos dispostos em fileiras, que servem para a fixação (6 a 7 em Anodontites trapesialis). Outra característica peculiar é a presença de apêndices filamentosos, ou filamento larval que, embora apresente diferenças morfológicas, pode ser considerado como uma estrutura homóloga em lasidium das espécies das duas famílias e, provavelmente, possui função tanto adesiva como trófica (FRYER, 1961; BONETTO; EZCURRA, 1962, 1965a; PARODIZ; BONETTO, 1963; CASTELLANOS; LANDONI, 1990; WÄCHTLER; DREHER-MANSUR; RICHTER, 2001).

Segundo Ihering (1891, apud PARODIZ; BONETTO, 1963) o apêndice filamentoso de lasidium de Anodontites consiste de duas amplas faixas planas que emerge lateralmente, parece projetar-se de uma posição mais ventral, na porção média coberta pela valva, expande-se e funde-se, após a concha, na base dos lobos ciliados anteriores. Assim, um anexo cônico é formado, com o ápice para o lado anterior abaixo da larva. As margens superiores das faixas ficam livres, formando um canal em forma de "V" que se estende 10 vezes mais que o corpo da larva e divide-se em duas ou três ramificações. De acordo com Wächtler, DreherMansur e Richter (2001), em Mutela (gênero africano) o filamento larval pode ser visto logo após a liberação da larva, enrolado sobre o corpo larval e mede cerca de 30 vezes mais que o comprimento do corpo. Embora, a complexidade do filamento larval de Anodontites estabeleça uma diferença significativa em relação a Mutela, a posição dos eixos do filamento é essencialmente similar (PARODIZ; BONETTO, 1963; BONETTO; EZCURRA, 1965a; WÄCHTLER; DREHER-MANSUR; RICHTER, 2001).

Uma das maiores diferenças entre lasidium de Anodontites e de Mutela encontra-se nas interações com o hospedeiro, durante a fase parasitária. A larva de Anodontites parasita formando cistos, enquanto a 
larva de Mutela sofre uma metamorfose completa em um estágio larval secundário fixada ao peixe por um par de apêndices tubulares denominados "haustoria". (PARODIZ; BONETTTO, 1963; WÄCHTLER; DREHER-MANSUR; RICHTER, 2001).

Em relação ao tamanho, a larva de Anodontites trapesialis forbesianus (Lea), estudada por Bonetto e Ezcurra (1962) é menor que a de Mutela, medindo em média $85 \mu \mathrm{m}$ ou $56,6 \%$ do tamanho da larva de Mutela estudada por Fryer (1959, 1961), que atinge em média $150 \mu \mathrm{m}$. Na América do Sul, em Anodontites trapezeus (Spix) e Mycetopoda siliquosa (Spix) estudados por Bonetto e Ezcurra (1965b), o tamanho do corpo larval é semelhante ao de Anodontites trapesialis forbesianus (Lea) com $85 \mu \mathrm{m}$ de comprimento. A larva de Mycetopoda legumem é maior em relação às demais larvas sul-americanas e, quando distendida, atinge um comprimento total de 148 a $166 \mu \mathrm{m}$, sem considerar o órgão adesivo (VEITENHEIMER-MENDES; MANSUR, 1978a).

\section{Desenvolvimento Parasitário}

Na América do Sul, o conhecimento sobre o desenvolvimento parasitário da lasidium resulta de poucos estudos de infestação experimental de peixes, destacando-se o realizado por Bonetto e Ezcurra (1962) para Anodontites trapesialis forbesianus (Lea) na Argentina.

No Brasil, Veitenheimer-Mendes e Mansur (1978b) estudaram o desenvolvimento parasitário e a lasidium de Mycetopoda legumen e SilvaSouza e Eiras (2002) descreveram a histopatologia da infestação de exemplares de Tilapia rendalli coletados no lago Igapó II, em Londrina, PR, e de um exemplar de Hypostomus regani em aquário, por lasidium de Anodontites trapesialis.

Quando terminam o desenvolvimento no "marsúpio", as larvas lasidium passam para o canal suprabranquial e atingem o ambiente externo por meio do sifão exalante (CASTELLANOS;
LANDONI, 1990). No ambiente, essas larvas necessitam encontrar um hospedeiro susceptível para completar o desenvolvimento (FRYER, 1970 apud DILLON, 2000). É provável que o tempo de sobrevivência da lasidium seja variável em alguns dias (WÄCHTLER; DREHER-MANSUR; RICHTER, 2001).

Segundo Bonetto e Ezcurra (1962), as larvas lasidium de Anodontites trapesialis realizam deslocamentos lentos e curtos durante o período que precede sua fixação no peixe, seu hospedeiro, por meio da atividade dos cílios dos lóbulos anteriores. As larvas de Anodontites são imediatamente ativadas pela presença do hospedeiro ou se cristais de $\mathrm{NaCl}$ são adicionados na água. Elas reagem com movimentos dos lóbulos anteriores para baixo e para cima e, mudando a forma do corpo de esférica para alongada, posicionam a estrutura adesiva para fora e em direção ao hospedeiro (WÄCHTLER; DREHER-MANSUR; RICHTER, 2001). Embora se prendam aos hospedeiros utilizando o órgão adesivo, o primeiro contato firme com o corpo do peixe é estabelecido pelos ganchos presentes nos lóbulos posteriores.

A implantação das larvas ocorre geralmente no tegumento, nas nadadeiras, nas escamas e nas brânquias, sendo mais freqüente nas nadadeiras, especialmente na caudal, na pele ou escamas do tronco (BONETO; EZCURRA, 1962; SILVASOUZA; EIRAS, 2002). O número de larvas que pode se desenvolver no peixe é elevado. Em um exemplar de Jenynsia lineata com $5,0 \mathrm{~cm}$ foram capturadas 860 larvas aderidas e em pleno desenvolvimento (BONETTO; EZCURRA, 1962).

Após a fixação, as larvas são envolvidas por um cisto. O fechamento do cisto é variável, podendo não ocorrer quando a larva está em contato direto com os tecidos do peixe. Também é variável a formação de um quisto a partir dos tecidos do hospedeiro, sendo a presença do cisto, no entanto, regra geral (BONETTO; EZCURRA, 1962). Em Anodontites, o epitélio do peixe forma um quisto que envolve 
a larva horas após a infecção (WÄCHTLER; DREHER-MANSUR; RICHTER, 2001). Análises histológicas realizadas por Silva-Souza e Eiras (2002) mostraram que as larvas lasidium ficam encistadas na epiderme e não ultrapassam a camada de epiderme basal.

Uma vez estabelecida sobre o peixe, a larva passa por uma série de transformações que conduz à formação do mexilhão juvenil e as larvas crescem durante o encapsulamento (FRYER, 1970 apud DILLON, 2000). Segundo Bonetto e Ezcurra (1962), 15 dias após a fixação começam a diferenciar-se internamente o pé e as brânquias. A valva apresenta finas estrias concêntricas sem linha de separação entre os dois lados. Após 19 a 28 dias, a larva alcança o estádio de mexilhão juvenil e se solta do peixe por movimentos do pé e dos músculos adutores. Às vezes, todo o cisto se desprende do peixe e a larva se libera no substrato, retornando à fase de vida livre.

De acordo com Silva-Souza e Eiras (2002), as lesões induzidas pelos parasitos são mínimas, especialmente considerando-se que a infecção é temporária e dura até que a larva complete a sua metamorfose. No entanto, parasitismo pelas larvas de bivalve pode reduzir o crescimento do hospedeiro, aumentar a sensibilidade do peixe a poluentes, possibilitar infecções secundárias por patógenos oportunistas, principalmente fungos e, dependendo da intensidade, resultar na morte do hospedeiro (SILVA-SOUZA; EIRAS, 2002).

\section{Considerações Finais}

Em Londrina e região tem-se verificado, nos últimos anos, a presença de elevado número de espécimes de Anodontites trapesialis em tanques de cultivos de peixes. Esses bivalves foram "acidentalmente" introduzidos nas pisciculturas e suas larvas têm causado sérios prejuízos. No entanto, nada se conhece sobre o seu desenvolvimento nesses ambientes. Além disso, por sua importância econômica e como indicadores de qualidade ambiental e, ainda, por constar da lista nacional de espécies ameaçadas de extinção, no Anexo I da Instrução Normativa $N^{\circ} 5$ - Ministério de Meio Ambiente de 2004 (BRASIL, 2004), ressaltase a necessidade de realização de estudos que enfoquem sua manutenção, reprodução e ciclo de desenvolvimento em diferentes ambientes aquáticos.

\section{Referências}

AVELAR, W. E. P. Functional anatomy of Fossula fossiculifera (D'Orbigny, 1843) (Bivalvia:Mycetopodidae). American Malacological Bulletin, Scranton, v. 10, n. 2, p. 129-138, 1993.

AVELAR, W. E. P.; COSTA, A. S. A.; COLUSSO, A. J.; DAL BÓ, C. M. R. Sexual dimorphism in Castalia undosa undosa Martens, 1827 (Bivalvia: Hyriidae). The Veliger, Los Angeles, v. 34, n. 2, p. 229-231, 1991.

AVELAR, W. E. P.; MENDONÇA, S. H. S. Aspects of gametogenesis of Diplodon rotundus gratus (Wagner 1827) (Bivalvia:Hyriidae) in Brazil. American Malacological Bulletin, Scranton, v. 14, n. 2, p. 157-163, 1998.

BEASLEY, C. R.; TÚRY, E.; VALE, W. G.; TAGLIARO, C. H. Reproductive cycle, management and conservation of Paxyodon syrmatophorus (Bivalvia: Hyriidae) from the Tocantis River, Brazil. Journal of Molluscan Studies, Oxford, v. 66, n. 3, p. 393-402, 2000.

BONETTO, A. A. El gênero Anodontites Bruguière (Mollusca, Pelecypoda) en el sistema hidrográfico Del Plata. Physis, Buenos Aires, v. 26, n. 73, p. 459-467, 1967.

BONETTO, A. A.; EZCURRA, I. D. El desarrollo del lasidium de Anodontites trapesialis forbesianus (Lea) (Mollusca, Lamellibranchiata). Physis, Buenos Aires, v. 23, n. 65, p. 195-203, 1962.

. Estudio comparado de las formas larvales de Mutelidae Ortmann y su significacion sistematica y zoogeografica. In: CONGRESSO LATINO AMERICANO DE ZOOLOGIA, 2., 1965, São Paulo. Anais... São Paulo: MZUSP, 1965a. v. 2, p. 55-71.

Notas malacológicas. III. 5) La escultura del periostraco en el genero Anodontites 6) el lasidium de Anodontites trapezeus (Spix) 7) el lasidium de Mycetopoda siliquosa (Spix). Physis, Buenos Aires, v. 25 , n. 69 , p. 197-204, 1965 b. 
BRASIL. Instrução normativa $\mathrm{N}^{0} 5$ - MMA, de 21 de maio de 2004. Anexo I - Lista nacional das espécies de invertebrados aquáticos e peixes ameaçadas de extinção. Diário Oficial \{da\} República Federativa do Brasil, Brasília DF, 28 maio 2004. Disponível em: <http:// www.ibama.gov.br/pndpa/legislacao.php?id_arq=123>. Acesso em: 18 jul. 2006.

CALLIL, C. T.; JUNK, W. J. Concentração e incorporação de mercúrio por moluscos bivalves Anodontites trapesialis (Lamarck, 1819) e Castalia ambigua (Lamarck, 1819) do Pantanal de Poconé-MT, Brasil. Biociências, Porto Alegre, v. 7, n. 1, p. 3-28, 1999.

CALLIL, C. T.; MANSUR, M. C. D. Ultrastructural analysis of the shells of Anodontites trapesialis (Lamarck) and Anodontites elongatus (Swaison) (Mollusca, Bivalvia, Etheroidea) from the Mato Grosso Pantanal Region, Brazil. Revista Brasileira de Zoologia, Curitiba, v. 22, n. 3, p. 724-734, 2005.

Gametogênese e dinâmica da reprodução de Anodontites trapesialis (Lamarck) (Unionoida; Mycetopodidae) no lago Baía do Poço, planície de inundação do rio Cuiabá, Mato Grosso, Brasil. Revista Brasileira de Zoologia, Curitiba, v. 24, n. 3, p. 825-840. 2007.

CASTELLANOS, Z. A.; LANDONI, N. La familia Mycetopodidae Gray, 1840 en La Republica Argentina. In: RINGUELET, R. A. (Ed.). Fauna de água Dulce de la Republica Argentina. Buenos Aires: FECIC, 1990. v. 16, p. 1-86.

CASTELLANOS, Z. J. A Contribucion al estudio biologico de almejas nacariferas Del Rio de La Plata. Revista Del Museo de La Plata, La Plata, v. 8, n. 60, p. 99-147, 1965.

DILLON, R. T. The ecology of freshwater molluscs. Cambridge: Cambridge Universitty, 2000.

FRYER, G. Development in a mutelid lamellibranch. Nature, Londres, n. 183, p. 1342-1343, 1959.

The developmental history of Mutela bourguignati (Ancey) Bourguignat (Mollusca: Bivalvia) Philosophical Transactions Royal Society of London. Series B: Biological Sciences, London, v. 244, n. 711, p. 259-298, 1961

HEBLING, N. J. The functional morphology of Anodontites trapezeus (Spix) and Anodontites trapesialis (Lamarck). (Bivalvia: Mycetopodidae). Boletim de Zoologia da Universidade de São Paulo, São Paulo, v. 15, n. 1s, p. 265-298, 1976.
JACOMINI, A. E. Bioacumulação do herbicida atrazina pelas espécies de bivalves limnicos Anodontites trapesialis (Lamarck, 1819) e Corbicula fluminea (Muller, 1774). 2002. Dissertação. (Mestrado em Biologia Comparada) - Universidade de São Paulo, Ribeirão Preto.

LOPES, J. L. C.; CASANOVA, I. C.; FIGUEIREDO, M. C. G.; NATHER, F. C.; AVELAR, W. E. P. Anodontites trapesialis: a biological monitor of organochlorine pesticides. Archives of Environmental Contamination and Toxicology, New York, v. 23, n. 3, p. 351-354, 1992.

MALDONADO, M.; ACOSTA, F.; ISURZA, L. J.; BARRA, C. Aspectos biológicos de Anodontites (Anodontites) soleniformes (Mollusca-Bivalvia) en el Arroyo Chipiriri (Cochabamba-Bolivia). Acta Limnologica Brasiliensia, Botucatu, v. 3, n. 2, p. 847863, 1990.

MANSUR, M. C. D. Gloquídio de Diplodon martensi (Ihering) (Mollusca, Bivalvia, Hyriidae) e seu ciclo parasitário. Revista Brasileira de Zoologia, Curitiba, v. 16, n. 2, p. 185-194, 1999.

MANSUR, M. C. D. Monocondylaea minuana Orbigny, 1835: variabilidade da concha e morfologia do sistema digestivo (Bivalvia, Mycetopodidae). Iheringia: Série Zoologia, Porto Alegre, n. 45, p. 3-25, 1974.

MANSUR, M. C. D.; SCHULZ, C.; GARCES, L. M. M. P. Moluscos bivalves de água doce: identificação dos gêneros do sul e leste do Brasil. Acta Biologica Leopoldensia, São Leopoldo, v. 9, n. 2, p.181-202, 1987.

MANSUR, M. C. D.; OLAZARRI, J. Redescrição, distribuição e preferências ambientais de Anodontites ferrarisi (Orbigny, 1835) revalidada (Bivalvia, Unionoida, Mycetopodidae). Iheringia: Série Zoologia, Porto Alegre, v. 79, n. 3, p. 12-29, 1995.

MANSUR, M. C. D.; PEREIRA, D. Bivalves límnicos da bacia do rio dos Sinos, Rio Grande do Sul, Brasil (Bivalvia, Unionoida, Veneroida e Mytiloida). Revista Brasileira de Zoologia, Curitiba, v. 23, n. 4, p. 11231147, 2006.

MARSHALL, W. B. New pearly fresh water mussels from South America. Proceedings of the United States National Museum, Washington, v. 61, p.1-9, 1922.

PARODIZ, J.; BONETTO, A. Taxonomy and zoogeographic relationships of the South American naiades (Pelecypoda:Unionacea and Mutelacea). Malacologia, Philadelphia, v. 1, n. 2, p. 179-213, 1963.

PEREDO, S.; PARADA, E. Reproductive cycle in the freshwater mussel Diplodon chilensis chilensis (Mollusca:Bivalvia). The Veliger, Los Angeles, v. 28, n. 4, p. 418-425, 1986. 
SILVA-SOUZA, Â.T.; EIRAS, J. C. The histopathology of the infection of Tilapia rendalli and Hypostomus regani (Osteichthyes) by Lasidium larvae of Anodontites trapesialis (Mollusca, Bivalvia). Memórias do Instituto Oswaldo Cruz, Rio de Janeiro, v. 97, n. 3, p. 431-433, 2002.

SIMONE, L. R. L. Anatomical characters and systematics of Anodontites tapesialis (Lamarck, 1819) from South America (Mollusca, Bivalvia, Uionoida, Muteloidea). Studies on Neotropical Fauna and Environment, Londres, v. 29, n. 3, p. 69-185, 1994.

SIMONE, L. R. L. Land and freshwater molluscs of Brazil. São Paulo: EGB/Fapesp, 2006.

TELLO-PANDURO, B.; GARCÍA-VASQUEZ, Y.; VIVANCO-MEDINA, M.; TABOADA, O. M. Ayr drying of clams (Anodontites trapesilais) and tilapia (Oreochromis niloticus) fillet. In: INTERNATIONAL DRYING SYMPOSIUM, 14., 2004. São Paulo. Proceedings... Campinas: Ourograf, 2004. p. 1977-1983. Disponível em: <http://www.feq.unicamp.br/ ids2004/ volC/pp\%201977-1983.pdf>. Acesso em: 6 fev. 2006.

TELLO-PANDURO, B.; GARCÍA-VASQUEZ, Y.; VIVANCO-MEDINA, M.; VITERI, J. D.; BAÇA, J. H.; TABOADA, O. M. Secado de tilpaia (Oreochromis sp.), almejas (Anodontites trapesialis) y camarón gigante (Macrobrachium rosenbergii). In: CONGRESSO IBEROAMERICANO VIRTUAL DE ACUICULTURA, 2., 2003. Anais eletrônicos... 2003. p. 775-783. Disponível em: <http://www.revistaaquatic.com/civa2003/coms/ listado.asp?cod=56>. Acesso em: 19 jul. 2006.

TOMAZELLI,A. C.; MARTINELLI, L. A.;AVELAR, W. E. A.; CAMARGO, P. B.; FOSTIER, A. H.; FERRAZ, E. S. B.; KRUG, F. J.; JÚNIOR, D. S. Biomonitoring of $\mathrm{Pb}$ and $\mathrm{Cd}$ in two impacted watersheds in Souttheast Brazil, using the freashwater mussel Anodontites trapesilais (Lamarck, 1819) (Bivalvia: Mycetopodidadae) as a biological monitor. Brazilian Archives of Biology and Technology, Curitiba, v. 46, n. 4, p. 673-684, 2003.
VEITENHEIMER-MENDES, I. L. Anodontites Bruguière, 1972 no Guaíba-RS (Bivalvia:Mycetopodidae) I. Anodontites trapesialis forbesianus (Lea, 1860). Iheringia: Série Zoologia, Porto Alegre, n. 44, p. 32-49, 1973a.

. Contribuição ao estudo do gênero Leila Gray, 1840 (Mycetopodiadae-Bivalvia). Iheringia: Série Zoologia, Porto Alegre, n. 42, p. 64-89, 1973 b.

VEITENHEIMER-MENDES, I. L.; MANSUR, M. C. D. Morfologia, histologia e ecologia de Mycetopoda legumen (MARTENS, 1888) - (Bivlavia, Mycetopodidae). Iheringia: Série Zoologia, Porto Alegre, n. 52, p. 33-71, 1978a.

Mycetopoda legumen (Martens, 1888): lasídio e desenvolvimento parasitário (Bivalvia:Mycetopodidae). Revista Brasileira de Biologia, Rio de Janeiro, v. 38, n. 3, p. 531-536, 1978 b.

VIVANCO, M. M.; ORDINOLA, A. A.; TABOADA, O. M. Secado natural y solar de almejas de agua dulce (Anodontites trapesialis). In: CONGRESSO IBEROAMERICANO VIRTUAL DE ACUICULTURA, 2., 2003. Anais... 2003. Disponível em: <http://www. revistaaquatic.com/civa2003/coms/listado.asp? $\operatorname{cod}=43>$. Acesso em: 19 jul. 2006.

WÄCHTLER, K.; DREHER-MANSUR, M. C.; RICHTER, T. Larval types and early postlarval biology in Naiads (Unionoida). In: WÄCHTLER, K. (Ed.). Ecology and evolution of the freshwater mussels unionoida, ecological studies. Berlin: Springer-Verlag, 2001. p. 93125. (Ecological Studies, 145). 
